\title{
Amino acids in the double Mannich reaction with anionic $\sigma$-complexes of 5,7-dinitro-8-hydroxyquinoline
}

\author{
C Ilya I. Ustinov, ${ }^{1+}$ Irina V. Shakhkeldyan, ${ }^{1}$ Nikolay V. Khlytin, ${ }^{1}$ \\ Yury M. Atroshchenko, ${ }^{1}$ and Konstantin I. Kobrakov ${ }^{2} *$ \\ ${ }^{1}$ Department of Chemistry. Tula State Lev Tolstoy Pedagogical University. Lenina St., 125. Tula, 300026. \\ Russia.Phone: +7 (4872)35-78-08.E-mail: bai2688@yandex.ru \\ ${ }^{2}$ Department of Organic Chemistry. State University of Russia. A.N. Kosygin (Technology. Design. Art). \\ Sadovnicheskaya St., 33. Moscow, 117997. Russia. Phone: +7 (495) 955-35-58. E-mail: kobrakovk@mail.ru
}

\begin{abstract}
*Supervising author; ${ }^{+}$Corresponding author
Keywords: 5,7-dinitro-8-hydroxyquinoline, Mannich reaction, anionic $\sigma$-complexes, amino acids, diazatricyclotridecans.
\end{abstract}

\begin{abstract}
The synthesis of new derivatives of 3-azabicyclononan is one of the urgent tasks of modern synthetic organic chemistry. 3-Azabicyclononan is a structural analogue of the cytisine alkaloid, which is a strong agonist of acetylcholine receptors. Among synthetic heterocycles containing a 3-azabicyclo[3.3.1]nonane fragment, compounds with different types of biological activity have been discovered at present: analgesic, anti-inflammatory, antimicrobial, antioxidant, and others. The introduction of a fragment of azabicyclononan into the amino acid structure can lead to a limitation of the conformational mobility of a new molecule, as a result of which the activity and selectivity of its interaction with the receptor will increase. We synthesized 2-(1,9-dinitro-8-oxo-6,11-diazatricyclo[7.3.1.0 $\left.0^{2,7}\right]$ trideca-2,4,6-trien-11-yl)acetic acid and 2-(1,9-dinitro-8oxo-13-(2-oxopropyl)-6,11-diazatricyclo[7.3.1.0.7.7trideca-2,4,6-trien-11-yl)acetic acid by the interaction of annionic $\sigma$-complexes 5,7-dinitro-8-hydroxyquinoline with glycine under Mannich condensation in high yield. At the beginning, when 5,7-dinitro-8-hydroxyquinoline $\mathrm{NaBH}_{4}$ was applied in DMF or acetone carbanion in DMSO, the corresponding anionic complexes were synthesized. The resulting adducts were isolated from the reaction mixture, dissolved in cold water, and an aminomethylating mixture consisting of formaldehyde and an amino acid was added. As a result, 3-azabicyclo[3.3.1]nonane derivatives are formed, annelated with a pyridine ring and containing an amino acid residue. By the methods of NMR and IR spectroscopy, as well as high-resolution mass spectrometry, the structure of the obtained compounds was proved. Thus, in the ${ }^{1} \mathrm{H} N M R$ spectra of the synthesized compounds, a signal of the proton of the carboxyl group in the form of a broadened singlet is detected in a weak spectral region. Equatorial and axial protons of an alicyclic fragment form a characteristic system of signals in the range $\delta 3.20-3.60 \mathrm{ppm}$. In the IR spectra of these molecules, the vibrational bands of carbonyl groups at $v 1720 \mathrm{~cm}^{-1}$, as well as the vibrational bands of the $\mathrm{C}-\mathrm{O}$ bond of the carboxyl group at $v 1198 \mathrm{~cm}^{-1}$, are fixed. The $\mathrm{m} / \mathrm{z}$ values in the high resolution mass spectra correspond to the molecular weights of the synthesized diazatricycclotridecans.
\end{abstract}

\section{References}

[1] E. Fattorusso, O. Taglialatela-Scafati. Modern alkaloids: structure, isolation, synthesis, and biology. John Wiley \& Sons. 2008. P.691.

[2] Perumal R. Venkatesa, M. Adiraj, Pandiyan P. Shanmuga. Synthesis, analgesic and anti-inflammatory evaluation of substituted 4-piperidones. Indian Drugs. 2001. Vol.38. No.3. P.156-159.

[3] J.J.F. Xaiver, K. Krishnasamy, C. Sankar. Synthesis and antibacterial, antifungal activities of some 2r,4cdiaryl-3-azabicyclo[3.3.1]nonan-9-one-4-aminobenzoyl hydrazones. Med. Chem. Res. 2012. Vol.21. No.3. P.345-350.

[4] P. Kodisundaram, A. Duraikannu, T. Balasankar. Cytotoxic and Antioxidant Activity of a Set of Hetero Bicylic Methylthiadiazole Hydrazones: A Structure-Activity Study. International journal of molecular and cellular medicine. 2015. Vol.4. No.2. P.128-137.

[5] B. Premalatha, D. Bhakiaraj, S. Elavarasan. Synthesis, spectral analysis, in vitro microbiological evaluation and antioxidant properties of 2, 4-diaryl-3-azabicyclo [3.3.1] nonane-9-one-O-[2, 4, 6tritertiarybutyl-cyclohexa-2, 5-dienon-4-yl] oximes as a new class of antimicrobial and antioxidant agents. J. Pharm. Res. 2013. Vol.6. No.7. P.730-735. 
AMINO ACIDS IN THE DOUBLE MANNICH REACTION WITH ANIONIC $\sigma$-COMPLEXES...

[6] A.V. Puchnin, M.A. Bastrakov, A.M. Starosotnikov, S.V. Popkov, S.A. Shevelev. Synthesis of pyrazoleand thiazole-annulated 3-R-1,5-dinitro-3-azabicyclo[3.3.1]nonanes. Russ. Chem. Bull. 2012. Vol.61. No.3. P.596-599.

[7] E. M. Asadulina, M.A. Bastrakov, V.V. Kachala, A.M. Starosotnikov, S.A. Shevelev. Synthesis of 3substituted 1,5-dinitro-3-azabicyclo-[3.3.1]nonanes containing a pyrazole fragment. Mendeleev Comm. 2008. Vol.18. No.4. P.213-214.

[8] E.M. Asadulina, M.A. Bastrakov, A.M. Starosotnikov, V.V. Kachala, S. A. Shevelev. Synthesis of 3-R1,5-dinitro-3-azabicyclo[3.3.1]nonanes fused to azoles. Russ. Chem. Bull. 2009. Vol.58. No.2. P.421-425.

[9] L.G. Mukhtorov, E.V. Ivanova, M.B. Karimov, M.B. Nikishina, I.V. Shahkeldyan, Yu.M. Atroshchenko, K.I. Kobrakov. Synthesis and structure of new derivatives of 2-chloro- $N$-(3-R-1,5- dinitro-8-oxo-3azabicyclo[3.3.1]non-6-en-7-yl)acetamides. Butlerov Communications. 2019. Vol.57. No.3. P.83-88. DOI: 10.37952/ROI-jbc-01/19-57-3-83

[10] I.I. Surova, E.V. Ivanova, Yu.M. Atroshchenko, G.V. Pestsov, K.I. Kobrakov. Synthesis and fungicidal activity of 2-methoxy-7-R-1,5-dinitro-3,7- diazabicyclo[3.3.1]non-2-ene. Butlerov Communications. 2017. Vol.51. No.8. P.65-70. DOI: 10.37952/ROI-jbc-01/17-51-8-65

[11] E.V. Ivanova, I.I. Surova, N.V. Hlytin, I.V. Blokhin, I.V. Shahkeldyan, Yu. M. Atroshchenko, K.I. Kobrakov. Bicyclic anionic $\sigma$-adduct of 2-hydroxy-3,5-dinitropyridine in the synthesis of new derivatives of 2,6-diazatricyclododekanes. Butlerov Communications. 2014. Vol.38. No.6. P.64-68. DOI: 10.37952/ROI-jbc-01/14-38-6-64

[12] I.E. Yakunina, I.V. Shakhkel'dyan, Yu.M. Atroshchenko, A.S. Rybakova, N.A. Troitskii, E.V. Shuvalova. Synthesis of Cytisine Structural Analogs by Mannich Condensation of 5,7-Dinitro-8hydroxyquinoline Anionic Adduct. Russ. J. Org. Chem. 2005. Vol.41. No.8. P.1238-1239.

[13] A.Yu. Medvedeva, I.E. Yakunina, Yu.M. Atroshchenko, A.N. Shumskii, I.V. Blokhin. Hydride adducts of dinitroquinolines in multicomponent Mannich reaction. Russ. J. Org. Chem. 2011. Vol.47. No.11. P.1733-1737.

[14] S. Clavier, Ø. Rist, S. Hansen, L.O. Gerlach, T. Högberg, J. Bergman. Preparation and evaluation of sulfur-containing metal chelators. Org. Biomol. Chem. 2003. Vol.1. P.4248-4253. 